\title{
Uncertainty estimation and in-house method validation of HPLC analysis of carotenoids for food composition data production
}

\author{
M. Graça Dias ${ }^{\mathrm{a}, *}$, M. Filomena G.F.C. Camões ${ }^{\mathrm{b}}$, Luísa Oliveira ${ }^{\mathrm{a}}$ \\ ${ }^{a}$ Laboratório de Bromatologia e Nutrição, Centro de Segurança Alimentar e Nutrição, Instituto Nacional de Saúde Dr. Ricardo Jorge \\ (INSA, I.P.), Av. Padre Cruz, 1649-016 Lisboa, Portugal \\ ${ }^{\mathrm{b}} C C M M / D Q B$ - Faculdade de Ciências da Universidade de Lisboa, 1749-016 Lisboa, Portugal
}

Received 23 March 2007; received in revised form 4 December 2007; accepted 12 December 2007

\begin{abstract}
The method for separation and quantitative determination of the main carotenoids in food by high-performance liquid chromatography (HPLC) was in-house validated. Tomato (Lycopersicon esculentum M.) as food matrix was used to demonstrate its linearity, repeatability, intermediate precision, detection and quantification limits, sensitivity and bias. In addition, stability of carotenoids was studied in function of temperature and time. Method accuracy was quantified through measurement uncertainties estimate based on this validation study. Furthermore, a study was conducted to evaluate variability coming from location in an experimental field composed by 12 subfields. The use of two metal free reverse phase columns and an organic mobile phase based on acetonitrile, methanol and dichloromethane enabled the separation of the six target compounds (trans- $\alpha$-carotene, trans- $\beta$-carotene, $\beta$-cryptoxanthin, all-lycopene, lutein, zeaxanthin) within a $30 \mathrm{~min}$ run; detection at $450 \mathrm{~nm}$ and external calibration allowed the quantification of the analytes. Carotenoids concentration and measurement uncertainty, in $\mathrm{mg} / 100 \mathrm{~g}$, in tomato varieties "lido" and "for salad" were, respectively, $1.0 \pm 0.14$ and $0.39 \pm 0.056$ for trans- $\beta$-carotene, $8 \pm 2.0$ and $2.3 \pm 0.57$ for all-lycopene and $0.10 \pm 0.017$ and $0.08 \pm 0.015$ for lutein; trans- $\alpha$-carotene, $\beta$-cryptoxanthin and zeaxanthin were not detected in both varieties (detection limits, in $\mu \mathrm{g} / 100 \mathrm{~g}, 0.81,0.57 \mathrm{and} 0.77$, respectively). For $\beta$-carotene and lutein, uncertainty associated with the entire process including small-scale within-region variation was statistically different, at a significance level of $5 \%$, from measurement uncertainty (which includes sampling in the laboratory).
\end{abstract}

(C) 2007 Elsevier Ltd. All rights reserved.

Keywords: Carotenoids; HPLC; Validation; Tomato; Analytical and pre-analytical uncertainties

\section{Introduction}

Carotenoids are a class of hydrocarbons (carotenes) and their oxygenated derivatives (xanthophylls) consisting of eight isoprenoid units joined in such a manner that the arrangement of isoprenoid units is reversed at the centre of the molecule. All carotenoids may be formally derived from the acyclic $\mathrm{C}_{40} \mathrm{H}_{56}$ structure having a long central chain of conjugated double bonds, by hydrogenation, dehydrogenation, cyclization or oxidation or any combination of these processes (IUPAC, 1974). Such system of con-

\footnotetext{
${ }^{*}$ Corresponding author. Tel.: +351 21 7526485; fax: +351 217508153 . E-mail address: m.graca.dias@insa.min-saude.pt (M.G. Dias).
}

jugated double bonds imparts them beautiful colours from yellow to red.

These natural pigments are present in fruits and vegetables and are essential components of plant photosynthetic apparatus. In human health their importance is related not only to their provitamin A activity but also to their antioxidant action (Riso, Visioli, Erba, Testolin, \& Porrini, 2004; Weisburger, 2002). In Europe the predominant carotenoids, both in food and serum, are $\alpha$-carotene, $\beta$-carotene, $\beta$-cryptoxanthin, lycopene, lutein and zeaxanthin (Granado, Olmedilla, Blanco, \& Rojas-Hidalgo, 1996; Olmedilla, Granado, Blanco, \& Rojas-Hidalgo, 1992). Among carotenoids, lycopene probably has the highest antioxidant capacity (Di Mascio, Kaiser, \& Sies, 1989). 
Tomato and tomato products are the main sources of dietary lycopene and also an important source of $\beta$-carotene (Krinsky \& Johnson, 2005).

The possible relation between the consumption of fruits and vegetables containing carotenoids and the human health (Cooper, 2004), the fact that carotenoids vary qualitative and quantitatively from food to food and that, within each species, their content generally varies largely with variety, maturity, soil and light intensity, determines the need for their analysis and the inclusion of this information on food composition databases. Nevertheless, the reliability of a substantial part of current data on food carotenoids still appears questionable (Rodriguez-Amaya, 2000). Carotenoid analysis inherent difficulty may contribute to this lack of reliability, mainly because of the large number of these compounds chemically very much alike occurring in food (around 60) and their susceptibility to isomerization and oxidation during analysis (carotenoids are sensitive to light, temperature, oxygen and active surfaces).

For consistent interpretation of an analytical method result it is necessary to evaluate the confidence that can be placed in it; this can be provided by the quantification of its accuracy (trueness and precision) combining bias with the measurement uncertainty estimate. To our knowledge, this approach has not yet been done to carotenoids determination. The Guide to the expression of Uncertainty in Measurement issued by the International Organization for Standardization (ISO, 1995) establishes the rules for evaluating and expressing uncertainty, a mathematical way which involves the exhaustive division of the analytical method into its steps to estimate all components separately and their subsequent combination applying the law of propagation of uncertainties. Although it is a very powerful tool (Analytical Methods Committee, 1995), it may be extremely complex when analytical methods include mass transfer steps, as in the present case (e.g. extraction, evaporation, etc.) that lack descriptive models of the behaviour of the analyte in the analytical system. The guide was interpreted for analytical chemistry by EURACHEM, which originally presented only this approach, but in the second edition (EURACHEM/CITAC, 2000) it already includes a second possibility that involves the treatment of interlaboratory information and also the use of information obtained from in-house validation of the analytical methods. This approach involving experiments that study the overall performance of the method, may not include contributions from all sources when estimating the variation, risking "double counting" when others contributions are studied separately. On the other hand the first approach (also named bottom-up) is not, a priori, more valid than a process that makes use of "whole method" performance parameters obtained during laboratory validation studies; experience shows that uncertainty estimations obtained by the mathematical analytical approach are often too small due to a tendency to omit some significant components (Eurolab, 2002). Ideally, of course, measurement uncertainties obtained either way should be similar. Quantification of the trueness (bias) and its associated measurment uncertainity with certified reference materials (CRMs), includes all current contributions to overall bias for a particular study but it is rarely clear which of these might vary in subsequent applications (in samples with different composition, homogeneity, analyte concentration) of the same method and thus contributing to uncertainty. On the other hand, difficulties related to CRMs, like price, limited number of matrices, analytes and concentration can be overcome estimating trueness indirectly by determining the amount of an added spike recovered from a sample matrix (Barwick \& Ellison, 1999).

Sampling foods for inclusion in a compositional database is one of the more demanding and difficult aspects of database preparation (Greenfield \& Southgate, 2003). Users of compositional databases require representative values for the composition of the foods consumed by the population for whom the database is being prepared. The primary objective in sampling is, therefore, to collect food samples that are representative ensuring that changes in composition do not take place between collection and analysis. Since all foods are biological materials and exhibit natural variations in composition, a secondary objective may be to document this variability as it relates to factors such as season, geography and cultivar. Such variations are to be expected and should not be confused with variations associated with the analytical conditions (Greenfield \& Southgate, 2003).

As an outcome of the arguments above, this study was planned aiming at contributing to the implementation of an HPLC method to produce analytical data on carotenoids composition of Portuguese fruits and vegetables to be included in food composition tables, by in-house validation using a tomato food matrix, studying sample and standards stability, evaluating measurement uncertainty and contributing to sampling planning.

\section{Materials and methods}

Studies were carried out to in-house validating an analytical method based on literature (Hart \& Scott, 1995; Scott, Finglas, Seale, Hart, \& Froidmont-Görtz, 1996) using tomato as food matrix. Small-scale within-region variation of carotenoids content was evaluated in a tomato variety. To deal with method high time and money consuming, carotenoids instability and HPLC prone faults, stability studies were done with samples and standards. Measurement uncertainty was estimated by a transversal approach (EURACHEM/CITAC, 2000; Silva, Santos, \& Camões, 2006) based on analytical method in-house validation data, namely, considering the intermediate precision and trueness; additionally uncertainties coming from variables not covered by in-house validation studies were estimated separately through the bottom-up approach. Method trueness was quantified using a certified reference material (lyophilized mixture of sweet corn, tomato and 
carrots), with certified value for $\alpha$-carotene, $\beta$-carotene and lutein and information value for lycopene and zeaxanthin, by participation in an interlaboratory study (baby food) for $\beta$-carotene and by the recovery of a non food native carotenoid, $\beta$-apo- $8^{\prime}$-carotenal, in each spiked sample analysed.

\subsection{Samples and sampling}

For repeatability, intermediate precision and stability studies, $1 \mathrm{~kg}$ of tomato (firm homogeneous ripe fruits) of the same variety (Lycopersicon esculentum M. var. "for salad") and identical maturation state was bought at a supermarket. The edible part (skin and seeds included) was prepared by elimination of the peduncle and surrounding area. Each tomato was then cut in two parts and separated in two groups, each one with half of each tomato. One group was immediately grinded in a knife mill, (Grindomix GM200, Retsch) $14 \mathrm{~s}$ at $7000 \mathrm{rpm}$ and carefully homogenised; 18 portions were immediately weighed, 9 were analysed on the same day, the other 9 were frozen at $-21^{\circ} \mathrm{C}$, under inert atmosphere (nitrogen) and were analysed $48 \mathrm{~h}$ later. The other group was refrigerated at $4{ }^{\circ} \mathrm{C}$ and analysed after $24 \mathrm{~h}$; a thin slice of the exposed tomato surface was removed, the remaining sample was grinded as previously described and 9 replicates analysed.

For small-scale within-region carotenoids variability evaluation, 12 lots (1 kg each) of firm ripe tomato (Lycopersicon esculentum M. var. Lido) samples produced from organic plants starters grown in a farm at the central/south region of Portugal, harvested in September, with an unitary mass in each lot ranging from $112.4 \mathrm{~g}$ to $200.9 \mathrm{~g}$ to take into account the possibility of carotenoids concentration being a function of the fruit size, were analysed. The 12 lots were harvested from 12 subfields at the same day and by the same person with the same criteria and kept refrigerated until the day of analysis (3-4 days) and were analysed in 2 successive days. Edible part was prepared as above and each tomato in a lot was cut longitudinally in quarters and two parts from opposite sides were ground and homogenized as above described (assuring similarity between the two sublots of quarters). Each lot composite sample was immediately analysed in duplicate.

\subsection{Analytical method}

All chemicals were at least of analytical grade; all liquid chemicals for HPLC were HPLC grade.

The homogenised sample replicates (approximately $10 \mathrm{~g}$ of each analytical sample were weighed in a balance with an acceptation criteria of $0.0002 \mathrm{~g}$ ) added with magnesium carbonate and internal standard, $\beta$-apo- $8^{\prime}$-carotenal, were extracted three times with tetrahydrofuran and methanol (each time with $50 \mathrm{~mL}$ of a mixture $1: 1, \mathrm{v} / \mathrm{v}$ ) using a batch high-performance homogeniser (ultra-turrax ${ }^{\circledR}$, IKA, Staufen, Germany) and vacuum-filtration. Exhaustive liquidliquid extraction (3 times energetically hand shook) was made to transfer analytes to a petroleum ether phase which was evaporated at $40{ }^{\circ} \mathrm{C}$ in a rotary evaporator; butylhydroxytoluene (BHT) was used as antioxidant at a concentration of $0.1 \%(\mathrm{w} / \mathrm{v})$. The residue was carefully dissolved in $2.5 \mathrm{~mL}$ of dichloromethane (DCM) and then diluted in $47.5 \mathrm{~mL}$ mobile phase without DCM, filtered through a $0.45 \mu \mathrm{m}$ PVDF syringe filter and injected in the HPLC system. When sample solution analyte concentration overcame calibration curve higher point, an adequate dilution was made. All manipulations were carried out under the cover of ordinary artificial light and direct sunlight, amber glass was used when feasible and extracts were always manipulated under yellow light and within the shortest time possible.

Carotenoids separation and quantification was done by reverse phase HPLC with photodiodes detection and chromatograms were extracted at $450 \mathrm{~nm}$. A Waters HPLC system, composed by a 600 Controller and Pump, a 717plus Auto Sampler, a 2996 Photodiode Array Detector and Empower software, was used; the mobile phase, acetonitrile:methanol (0.05 M ammonium acetate):dichloromethane, 75:20:5, v/v/v, containing $0.1 \%$ BHT and $0.05 \%$ triethylamine, was filtered through a $0.45 \mu \mathrm{m}$ PTFE membrane filter and degassed in an ultrasonic bath. The columns used were a Waters Spherisorb ODS2 PEEK (poly ether ether ketone) lined (Alltech, cat. no. 8161), $5 \mu \mathrm{m}$, $100 \times 4.6 \mathrm{~mm}$ connected to a reverse phase $\mathrm{C} 18$ (Vydac, cat. no. 201TP54), $5 \mu \mathrm{m}, 250 \times 4.6 \mathrm{~mm}$. Flow rate was $1.5 \mathrm{~mL} / \mathrm{min}$, injection volume $50 \mu \mathrm{L}$ and stop time $30 \mathrm{~min}$. Two injections per vial were made.

Sample carotenoids were identified using the HPLC system software by comparing their retention time (RT) and visible absorption spectra $\left(\lambda_{\max }\right.$ and spectral fine structure according to literature (Britton, 1995) was also used) with those of carotenoids standards. Sample peak purity was checked using the HPLC system software to adjust the integration. The quantification was done by external standard calibration, based on peak areas. $\beta$-apo- $8^{\prime}$-carotenal was used as an internal standard to control the analytical process and its recovery was used to correct carotenoids concentration, assuming a behavioural similarity with the substances under study. $\alpha$-Carotene, $\beta$-carotene, lycopene and lutein were purchased from Sigma Chemical Co., $\beta$ apo- $8^{\prime}$-carotenal from Fluka Chemicals, zeaxanthin and $\beta$-cryptoxanthin from Carl Roth. Stock solutions were prepared according to literature (Hart \& Scott, 1995) and their concentrations were determined with a Hitachi U-2000 spectrophotometer (acceptation criteria of 0.007 of absorbance, at $440 \mathrm{~nm}$ and 0.521 of absorbance, the most unfavourable measuring situation) using the following extinction coefficients $-E_{1 \mathrm{~cm}}^{1 \%}$ and wavelengths: ethanolic solution of lutein, $2550(445 \mathrm{~nm})$; hexane solution of zeaxanthin, $2480(451 \mathrm{~nm}), \beta$-cryptoxanthin, $2460(451 \mathrm{~nm})$, lycopene, $3450(472 \mathrm{~nm}), \alpha$-carotene, $2800(444 \mathrm{~nm}), \beta$-carotene $2560(450 \mathrm{~nm})$. Individual working solutions of each carotenoid were injected in the HPLC system on the first day for purity check (purity, based on peak area of the 
individual carotenoid to sum of all chromatogram peak areas ratio was: for trans- $\beta$-carotene and lutein, 98.4\% and $98.9 \%$, respectively; for trans- $\alpha$-carotene, $\beta$-cryptoxanthin, all-lycopene and zeaxanthin, $100 \%$ ) and the concentrations of the standard solutions were corrected accordingly. Six levels of working calibration solutions with a mixture of the six carotenoids (concentrations $0.05-4 \mu \mathrm{g} / \mathrm{mL}$, equally distanced) were injected daily to build the calibration curves by the least squares method, $Y=\left(a \pm t s_{\mathrm{a}}\right)+\left(b \pm t s_{\mathrm{b}}\right) X$, where $Y$ is the peak area, in $\mu \mathrm{V}$ s and $X$ is the concentration (also called $C$ below), in $\mu \mathrm{g} / \mathrm{mL}$ of extract, a is the intercept and $b$ is the slope, the $t$ value is taken at the confidence level of $95 \%$ for $(n-2)$ degrees of freedom, $s_{\mathrm{b}}$ (standard error of the slope) $=$ $s_{y / x} /\left[\Sigma\left(x_{i}-x_{\text {mean }}\right)^{2}\right]^{1 / 2}, s_{\mathrm{a}}$ (standard error of the intercept $)=$ $s_{y / x} \Sigma x_{i}^{2} /\left[n \Sigma\left(x_{i}-x_{\text {mean }}\right)^{2}\right]^{1 / 2}$ and $s_{y / x}$ (standard error of $y$ residuals $)=\left[\Sigma\left(y_{i}-\hat{y}_{i}\right)^{2} /(n-2)\right]^{1 / 2}($ Miller \& Miller, 1993).

Sample solution analyte concentration, in $\mu \mathrm{g} / \mathrm{mL}\left(C_{\mathrm{si}}\right)$ was obtained by calibration curve interpolation.

The analyte concentration in samples, $\mathrm{C}$, in $\mathrm{mg} / 100 \mathrm{~g}$, was calculated using the following equation:

$\mathrm{C}=\frac{C_{\mathrm{si}} V_{\mathrm{f}}}{m R d} \times 10$

where $C_{\mathrm{si}}$ is the sample solution concentration $(\mu \mathrm{g} / \mathrm{mL}), V_{\mathrm{f}}$ is the final volume $(\mathrm{mL}), m$ is the sample mass $(\mathrm{g}), R$ is the $\beta$-apo- $8^{\prime}$-carotenal recovery (\%), $d$ is the dilution and 10 is a unit conversion constant.

\subsection{Method in-house validation}

On a first approach the limits of detection and quantification were determined based on two different methods: method A - based on the calibration curve (Miller \& Miller, 1993) and method B - based on detector signal to noise ratio. The detection limit obtained by method A was given by the expression $3.3 s_{y / x} /$ slope, and was based on the assumptions that, the standard deviation of the signal of a solution with a concentration near the blank is roughly the standard deviation of $y$-residuals $\left(s_{y / x}\right)$, there is a normal distribution of the signal at this concentration, the probability of $5 \%$ of occurring error type $\alpha$ or $\beta$, and that the curve intercepts zero. It was estimated as the arithmetic mean of the different detection limits obtained with the different calibration curves, freshly prepared each day. The quantification limit was estimated using the factor 10 instead of 3.3. The detection limit obtained by method $\mathrm{B}$ was calculated as $3 h_{\text {noise }} C / h_{\text {peak }}$, where $h_{\text {noise }}$ is the mean height of the noise and $\mathrm{C} / \mathrm{h}_{\text {peak }}$ is the concentration of a solution giving a peak with roughly 5 times the height of the noise to the height of that peak ratio; for the quantification limit the factor 3 was substituted by 10 .

The quantification limits of carotenoids present in the food matrix were confirmed by preparing and analysing 10 independent standard solutions at the lowest quantification limits estimated by the above methods and comparing the relative standard deviations obtained with sample repeatability standard deviation. The quantification limits of carotenoids absent in the matrix were confirmed by spiking matrix samples at the lowest quantification level obtained by the above methods and comparing the relative standard deviations with a limit of $10 \%$. Repeatability and intermediate precision were estimated considering within, and within and between day variations, respectively, according to ISO $5725-1$ to 6,1994 (E). Twenty seven sample measurements were made in 3 different days, 9 replicates each day; mobile phase and calibration solutions were prepared each day.

Bias was evaluated by duplicate analysis in four different days of the Certified Reference Material (CRM) 485 (lyophilised mixed vegetable preparation of sweet corn, tomato and carrots) from former European Commission BCR, the Community Bureau of Reference, with certified values for trans- $\alpha$-carotene $(1.05 \mathrm{mg} / 100 \mathrm{~g})$, trans- $\beta$-carotene (2.37 $\mathrm{mg} / 100 \mathrm{~g})$ and lutein $(1.25 \mathrm{mg} / 100 \mathrm{~g})$, and information values for total-lycopene $(1.42 \mathrm{mg} / 100 \mathrm{~g})$ and zeaxanthin $(0.97 \mathrm{mg} / 100 \mathrm{~g})$. Trueness was also checked by participating in a round of BIPEA (Bureau InterProfessionnel d'Etudes Analytiques) proficiency scheme (15 participants) for the determination of $\beta$-carotene in baby food (assigned value $-2.55 \mathrm{mg} / 100 \mathrm{~g}$ ). Bias was quantified through $z$-score (difference between the value obtained by the laboratory and the best estimate of the "true" concentration (assigned CRM or BIPEA value) to standard deviation of data obtained in the interlaboratory study for the CRM or BIPEA quotient); considering a 95\% confidence interval, $z$-score is acceptable for values between -2 and 2. Indirectly, bias was estimated by a recovery test, spiking each sample, after weighing and before extraction, with $\beta$-apo8 '-carotenal (a carotenoid similar to those analysed and not present in test samples).

Detector sensitivity, the signal output per unit concentration, was given by the slope of the regression line.

Linearity was checked between $0.05 \mu \mathrm{g} / \mathrm{mL}$ and $4 \mu \mathrm{g} / \mathrm{mL}$ using six levels of calibration. Ten independent calibration solutions of the lowest, ten of the highest and one of each intermediate calibration level were analysed by HPLC system, each one injected in duplicate. Signal variances of upper and lower calibration limits were calculated and the homogeneity of variances was evaluated through an $F$-test at a significance level of $1 \%$. Linear calibration function was calculated. Linearity was tested with three criteria: experimental calibration points lying, under and above, close to the calculated linear regression line; productmoment correlation coefficient equal or higher than 0.9975 ; and at a significance level of $1 \%$ a non-linear calibration function does not lead to a significantly better adjustment, tested by an $F$-test (ISO 8466-1, 1990).

\subsection{Carotenoids stability studies}

To deal with eventual equipment failure, two studies were conducted, one using standard solutions and the other 
using tomato sample solutions. To evaluate standards stability working standard solutions at six levels of concentration, for the six analytes, at the conditions: $36^{\circ} \mathrm{C}$ (an extreme laboratory temperature in summer), and at 4 $8{ }^{\circ} \mathrm{C}$ (remaining solutions storing conditions) were analysed. A paired two-tailed $t$ test was done to compare the concentration signals obtained for the six standards at $t=0 \mathrm{~h}$ with those obtained at $t=6 \mathrm{~h}, 12 \mathrm{~h}, 24 \mathrm{~h}$ and 41 $\mathrm{h}$, at $36^{\circ} \mathrm{C}$ and at $t=24 \mathrm{~h}$ at $4{ }^{\circ} \mathrm{C}$. To evaluate the stability of tomato sample solutions containing lutein, $\beta$-carotene and lycopene they were analysed immediately after preparation and after $24 \mathrm{~h}$ storage at $4{ }^{\circ} \mathrm{C}$ and concentrations were evaluated by comparing the relative error (Er), Eq. (2), with injector repeatability relative standards deviation.

$E_{r}=\frac{C_{24}-C_{0}}{C_{0}} \times 100$

where $C_{24}$ is the concentration after $24 \mathrm{~h}$ storage at $4{ }^{\circ} \mathrm{C}$ and $C_{0}$ is the concentration before storage.

Since tomato is a perishable product and in order to guarantee the reliability of precision studies, an one-way ANOVA statistical test was applied to repeatability and intermediate precision results to evaluate the differences between the 3 mean results of 9 replicates analysed each day, each day corresponding to a storage time (i.e. $0 \mathrm{~h}$, $24 \mathrm{~h}$ at $4{ }^{\circ} \mathrm{C}$ and $48 \mathrm{~h}$ at $-21{ }^{\circ} \mathrm{C}$ ).

\subsection{Analytical uncertainty and natural variation}

Measurement uncertainty was estimated based on intralaboratory data: studies of precision, performance data of the analytical process and quantification of individual components. Contribution from stock standard solution concentration is not covered by precision data and it was estimated individually by a mathematical model (bottomup approach). According to this model, the combined standard uncertainty $u_{\mathrm{s}}(y)$ of a value of $y$ is related to the uncertainty estimation of the independent parameters $x_{1}, \ldots, x_{n}$, on which it depends by the following equation:

$$
u_{s}\left(y\left(x_{1}, \ldots, x_{n}\right)\right)=\sqrt{\sum_{i=1, \ldots, n} c_{i}^{2} u\left(x_{i}\right)^{2}}
$$

where: $y\left(x_{1}, \ldots, x_{n}\right)$ is a function of several parameters $x_{1}, \ldots, x_{n}, \boldsymbol{c}_{\boldsymbol{i}}$ is a sensitivity coefficient evaluated as $c_{i}=\partial y /$ $\partial x_{i}$ (partial derivative of $y$ with respect to $x_{i}$ ) and $u\left(x_{i}\right)$ is the uncertainty in $\boldsymbol{x}_{\boldsymbol{i}}$, expressed as a standard deviation.

This general procedure was applied to calculate uncertainty associated to stock standard solution concentration $\left(C_{\text {stock }}\right)$ which is obtained from the following equation:

$C_{\text {stock }}(\mu \mathrm{g} / \mathrm{mL})=\frac{\text { Absorbance } V_{2}}{E_{1 \mathrm{~cm}}^{1 \%} V_{1}} \times 10,000$

where $V_{2}$ is the re-dissolution solvent volume $(\mathrm{mL})$ measured with a $10 \mathrm{~mL}$ pipette, $V_{1}$ is the initial volume $(\mathrm{mL})$ measured with a pipette of $1 \mathrm{~mL}, E_{1 \mathrm{~cm}}^{1 \%}$ is the extinction coefficient and 10,000 is a unit conversion constant.
After estimation of all sources of uncertainty they were joined according to their laws of combination (EURACHEM/CITAC, 2000), obtaining the combined standard uncertainty $\left(u_{\mathrm{c}}\right)$.

The expanded uncertainty $\left(U_{\mathrm{c}}\right)$ was calculated as $U_{\mathrm{c}}=k u_{\mathrm{c}}$, where $k$ is the coverage factor (EURACHEM/CITAC, 2000).

Natural variation was evaluated based on small-scale within-region carotenoids variability. The validated method was applied to analyse 12 tomato (Lycopersicon esculentum M. var. Lido) samples harvested in 12 subfields of the same region and the variance, $s^{2}$, for each analyte was calculated.

Assuming a similar behaviour for different varieties of the same matrix and uncertainty proportional to concentration (concentrations above the quantification limit), measurement uncertainty, $u_{\mathrm{c}}$, was estimated for each analyte in these samples. Considering the experimental design the maximum expected contribution of analytical uncertainty to the observed variance, $s^{2}$, is the estimated $u_{\mathrm{c}}^{2}$. The obtained values were compared through a $F$-test, where $\mathrm{s}$ has 11 degrees of freedom and $u_{\mathrm{c}}$ has approximately infinite degrees of freedom (because $u_{\mathrm{c}}$ collected information from the combination of the various sources of uncertainty).

\section{Results and discussion}

\subsection{Chromatograms}

The chromatograms show that the method can successfully separate, the seven carotenoids in a mixture of standards, and the carotenoids present in a tomato sample with the internal standard added (Fig. 1). Retention times (in minutes) were 5.3, 5.7, 7.0, 11.2, 15.6, 23.8 and 25.3, respectively for lutein, zeaxanthin, $\beta$-apo-8'-carotenal, $\beta$-cryptoxanthin, lycopene, trans- $\alpha$-carotene and trans- $\beta$-carotene.

\subsection{Linearity}

The difference between the variances of the signal obtained for concentration solutions $0.05 \mu \mathrm{g} / \mathrm{mL}$ and 4 $\mu \mathrm{g} / \mathrm{mL}$ was not significant at a $1 \%$ level of significance (considering the different carotenoids, the minimum value of $P$ was 0.10 ). The non-linear calibration functions did not lead to a significantly better adjustment (significance level $1 \%$ ), confirming the high linearity verified visually by the graphical representation of the six experimental calibration levels and by the statistics product-moment correlation coefficients of first order regression functions $(r \geqslant 0.9985)$.

The parameters of the regression equations obtained for the calibrations curves are shown in Table 1.

Although point $(0,0)$ was not used to build the calibration curves, this point is included in the confidence limits for the intercept (confidence level 95\%) in all regression lines. Zeaxanthin showed the smallest determination coefficient $\left(r^{2}=0.997\right)$, but still acceptable $\left(r^{2} \geqslant 0.995\right)$ (Miller \& Miller, 1993). 


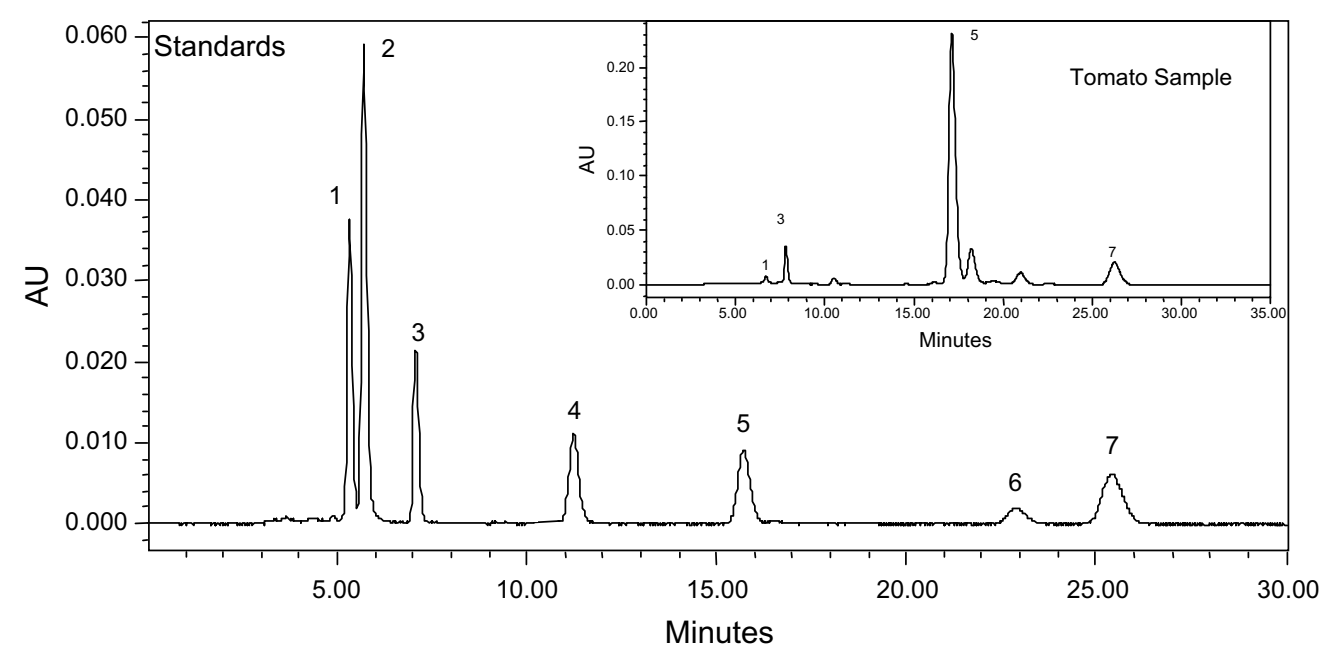

Fig. 1. Chromatogram of a standard mixture and a tomato sample solution showing carotenoids elution profile $-(1)$ lutein $(t=5.313 \mathrm{~min}, c=0.71 \mu \mathrm{g} /$ $\mathrm{mL})$, (2) zeaxanthin $(t=5.686 \mathrm{~min}, c=1.16 \mu \mathrm{g} / \mathrm{mL})$, (3) $\beta$-apo- $8^{\prime}$-carotenal $(t=7.045 \mathrm{~min})$, (4) $\beta$-cryptoxanthin $(t=11.178 \mathrm{~min}, c=0.48 \mu \mathrm{g} / \mathrm{mL}),(5)$ lycopene ( $t=15.600 \mathrm{~min}, c=0.62 \mu \mathrm{g} / \mathrm{mL})$, (6) trans- $\alpha$-carotene $(t=22.759 \mathrm{~min}, c=0.14 \mu \mathrm{g} / \mathrm{mL}),(7)$ trans- $\beta$-carotene $(t=25.305 \mathrm{~min}, c=0.51 \mu \mathrm{g} / \mathrm{mL})$. Chromatographic conditions as referred in Section 2.

Table 1

Limits of detection and quantification and regression curve data

\begin{tabular}{|c|c|c|c|c|c|c|}
\hline Parameter & trans- $\alpha$-Carotene & trans- $\beta$-Carotene & $\beta$-Cryptoxanthin & All-lycopene & Lutein & Zeaxanthin \\
\hline $\begin{array}{l}\text { Detection limit } \\
(\mu \mathrm{g} / \mathrm{mL}) \\
(\mu \mathrm{g} / 100 \mathrm{~g})\end{array}$ & $\begin{array}{l}0.0162 \\
0.81\end{array}$ & $\begin{array}{l}0.0182 \\
0.91\end{array}$ & $\begin{array}{l}0.0115 \\
0.57\end{array}$ & $\begin{array}{l}0.0166 \\
0.83\end{array}$ & $\begin{array}{l}0.0132 \\
0.66\end{array}$ & $\begin{array}{l}0.0154 \\
0.77\end{array}$ \\
\hline $\begin{array}{l}\text { Quantification limit } \\
(\mu \mathrm{g} / \mathrm{mL}) \\
(\mu \mathrm{g} / 100 \mathrm{~g})\end{array}$ & $\begin{array}{l}0.0492 \\
2.46\end{array}$ & $\begin{array}{l}0.0553 \\
2.76\end{array}$ & $\begin{array}{l}0.0347 \\
1.74\end{array}$ & $\begin{array}{l}0.0504 \\
2.52\end{array}$ & $\begin{array}{l}0.0399 \\
1.99\end{array}$ & $\begin{array}{l}0.0466 \\
2.33\end{array}$ \\
\hline
\end{tabular}

$N$ - number of freshly prepared curves in different days from standards also freshly prepared; $a$-intercept; $b$ - slope; $r$ - product-moment correlation coefficient; $t$-statistics parameter; $s_{\mathrm{a}}-$ standard deviation of intercept; $s_{\mathrm{b}}-$ standard deviation of slope; $s_{\mathrm{r}}-$ standard deviation of product-moment correlation coefficient.

\subsection{Limits of detection and quantification}

Except for $\beta$-cryptoxanthin, the detection and quantification limits were always higher for method A (based on standard deviation of $y$-residuals $\left(s_{y / x}\right)$ of the calibration curve to slope ratio) than for method B (based on signal to noise ratio); experimental confirmation of quantification limits was performed at the lowest concentration level obtained by the above methods. The relative standard deviations were $2.7 \%$ for $\beta$-carotene, $5.0 \%$ for lycopene and $3.0 \%$ for lutein under sample repeatability relative standard deviation 4.0, 6.0, 3.1, respectively. For carotenoids not found in tomato, the relative standard deviations were $5.0 \% \beta$-cryptoxanthin, $5.1 \% \alpha$-carotene and $5.3 \%$, zeaxanthin all below the $10 \%$ limit.

The obtained detection and quantification limits are presented in Table 1.
The Limits of Quantification obtained with this analytical method, as described, do not allow complying with the suggested limit of $1 \mu \mathrm{g} / 100 \mathrm{~g}$ for carotenes in food composition databases (Greenfield \& Southgate, 2003). In order to conform with the above recommendation the reconstitution volume should be $1.7 \mathrm{~mL}$, instead of $50 \mathrm{~mL}$, which is not practicable for the method as designed (the minimum feasible reconstitution volume would be $5 \mathrm{~mL}$ ) and the uncertainty should be lower than $1 \mu \mathrm{g} / 100 \mathrm{~g}$ which considering matrix interferences is questionable.

\subsection{Repeatability and intermediate precision}

Sample stability study results (see below) insured that only the analytical process random errors influenced the values obtained for repeatability and intermediate precision. 
The analytical results (raw data) of repeatability and intermediate precision as well as statistics such as mean, relative standard deviations of the mean, repeatability and intermediate precision and stability significance test for tomato matrix are presented in Table 2 .

\subsection{Sensitivity}

According to results presented in Table 1 the method is $33 \%$ less sensitive for lycopene than it is for $\alpha$-carotene; this result was expected since lycopene is the most unsaturated acyclic carotenoid, its absorption maximum being therefore at a wavelength around $473 \mathrm{~nm}$ whereas the measurement wavelength is $450 \mathrm{~nm}$. Given that the integration algorithm of HPLC system software always needs manual adjustment, measurement wavelength was chosen in order to be as close as possible to the absorption maximum of the analysed carotenoids more frequently present in food matrices, with the purpose to avoid the extra work of extracting and integrating chromatograms at different wavelengths.

\subsection{Bias}

Laboratory analysis of CRM 485 gave the following mean results in $\mathrm{mg} / 100 \mathrm{~g}$ : trans- $\alpha$-carotene, 1.05 ; trans- $\beta$ carotene, 2.39; all-lycopene, 1.16; lutein, 1.05 and zeaxanthin, 0.83 . BIPEA test material analysis gave a $\beta$-carotene result of $1.86 \mathrm{mg} / 100 \mathrm{~g}$.
The $z$-scores for CRM 485 reference material were, -0.061 for trans- $\alpha$-carotene, 0.097 for trans- $\beta$-carotene, -1.53 for lutein, -0.64 for zeaxanthin, -0.66 for all-lycopene; the reference material did not contain $\beta$-cryptoxanthin. A $z$-score of -0.36 was obtained for $\beta$-carotene in BIPEA proficiency testing scheme participation. All obtained $z$-scores were satisfactory.

Recovery values, based on the addition of $\beta$-apo- $8^{\prime}$-carotenal were $93.7 \%(s=10.5 \%, n=48)$, which are in good agreement with values referred in the literature (Hart \& Scott, 1995) for different vegetable matrices $(87.8 \%$, $s=8.21 \%, n=127$ ) and it is not statistically different from $100 \%$ at a significance level of 0.05 . Identical behaviour for added and natural carotenoids was assumed. The three approaches for trueness quantification, each one with limitations, agree with the fact that the laboratory method performance has no significant bias.

\subsection{Standards solutions stability}

At a significance level of 5\% and for all carotenoids, there were non-significant differences in the detector response to the different concentration levels of standards solutions up to $6 \mathrm{~h}$ at $36^{\circ} \mathrm{C}(0.06<P<0.71)$, lycopene presenting the worst performance, and at least up to $24 \mathrm{~h}$ at $4{ }^{\circ} \mathrm{C}(0.21<P<0.24)$. At $36{ }^{\circ} \mathrm{C}$ there is a significant difference at $t=12 \mathrm{~h}$ (lycopene and $\alpha$-carotene), $t=24 \mathrm{~h}$

Table 2

Carotenoids in tomato - Precision data (raw data and statistics)

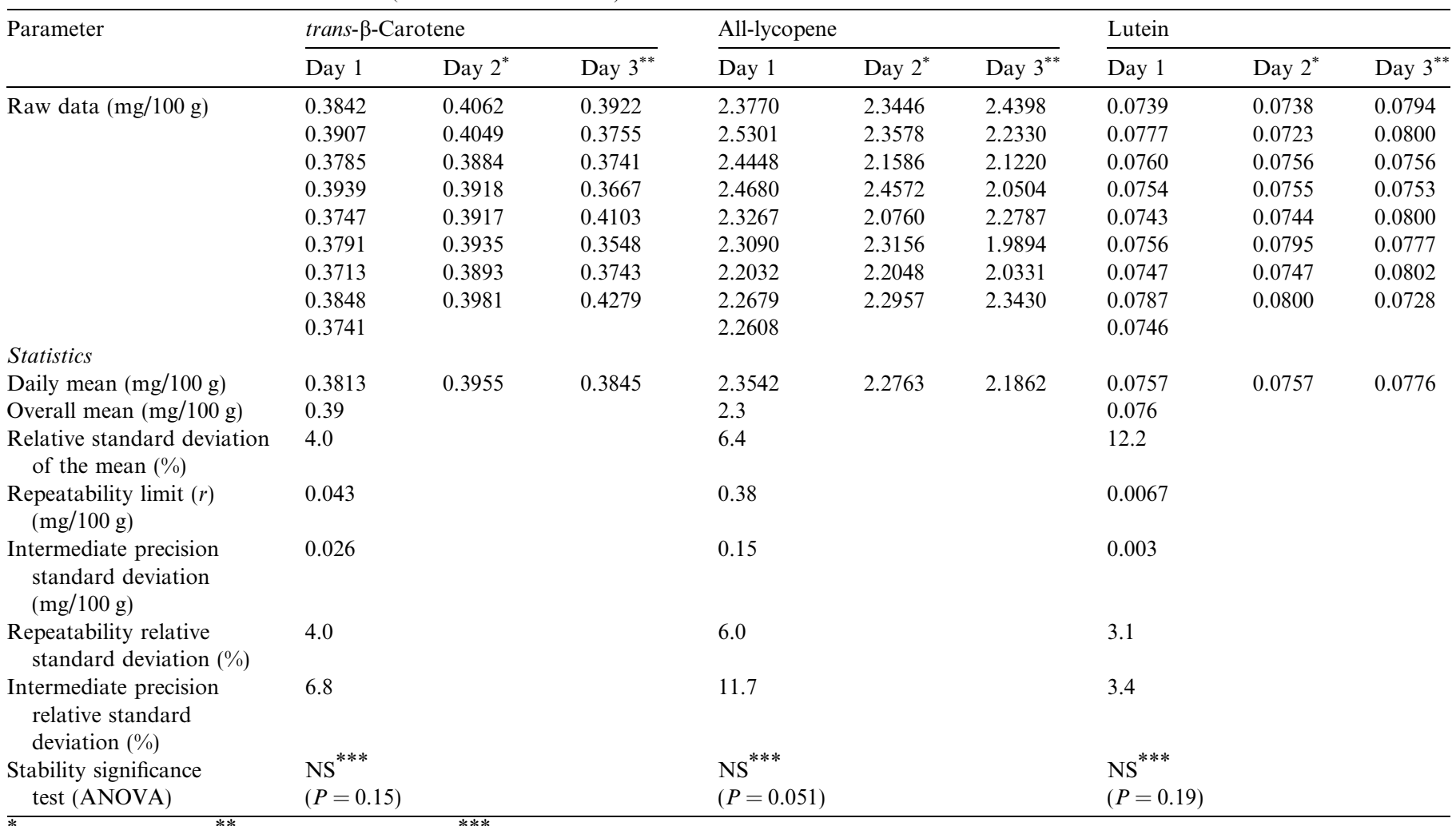

${ }^{*}$ Stored $24 \mathrm{~h}$ at $4{ }^{\circ} \mathrm{C} ;{ }^{* *}$ stored $48 \mathrm{~h}$ at $-21{ }^{\circ} \mathrm{C} ;{ }^{* * *}$ significance level $-5 \%$; NS, not significant. 
(all except $\beta$-carotene) and $t=41 \mathrm{~h}$ (all). Standard solutions can be kept at least $24 \mathrm{~h}$ at $4{ }^{\circ} \mathrm{C}$ and only up to $6 \mathrm{~h}$ at $36^{\circ} \mathrm{C}$.

\subsection{Sample solutions stability}

Comparing the results for sample solutions immediately analysed and after storing $24 \mathrm{~h}$ at $4{ }^{\circ} \mathrm{C}$, the relative error of the carotenoids concentrations at the two different temperatures in the samples varied between $0.2 \%$ ( $\beta$-carotene) and $2 \%$ (lycopene); these values are similar to the ones of replicate injections on the HPLC system, therefore solutions are stable at least $24 \mathrm{~h}$, if stored in the refrigerator.

\subsection{Tomato samples stability}

At a 5\% significance level the one-way ANOVA test allowed to conclude that there were non-significant differences between the three mean values $(P$ values: 0.15 for $\beta$-carotene; 0.051 for lycopene and 0.19 for lutein). Tomato samples may be stored at $4{ }^{\circ} \mathrm{C}$ at least for $24 \mathrm{~h}$ and at $-21^{\circ} \mathrm{C}$ at least for $48 \mathrm{~h}$, prior to analysis.

\subsection{Analytical uncertainties}

Sources of uncertainty such as those arising from balances and volumetric measuring devices are covered by the precision and recovery studies since all these instruments are under regular control and several have been used. Sample homogeneity and linear calibration curve interpolation uncertainties are included in the precision uncertainty because various replicates from the same sample were analysed and standards were injected each day.

Uncertainty coming from stock standard solution was studied separately because: work standards were prepared from it, stock standard solution concentration $\left(C_{\text {stock }}\right)$ was determined spectrophotometrically only at its preparation day and it involves a dissolution solvent change. Uncertainty was calculated taking in account: a spectrophotometer acceptation criteria of 0.007 and a rectangular distribution for uncertainty arising from absorbance; a confidence interval (level of confidence not provided) of $0.05 \mathrm{~mL}$ and $0.007 \mathrm{~mL}$, and a rectangular distribution for volumes of $10 \mathrm{~mL}$ and $1 \mathrm{~mL}$, respectively for uncertainty coming from measurement with pipettes; a negligible uncertainty arriving from the extinction coefficient (not considered).

Uncertainty associated to bias was calculated based on the standard deviation of the recovery of added $\beta$-apo- $8^{\prime}-$ carotenal in this matrix $(n=48)$.

Long term influences of environmental temperature are not considered since these samples are perishable.

The results are presented in the Uncertainties Histogram shown in Fig. 2. For the tomato matrix studied, the combined relative uncertainty $\left(u_{\mathrm{c}} / C\right.$, where $u_{\mathrm{c}}$ is the measurement uncertainty and $C$ is the concentration) for different analytes was 0.073 for $\beta$-carotene, 0.12 for lycopene and 0.088 for lutein. The major contribution to uncertainty

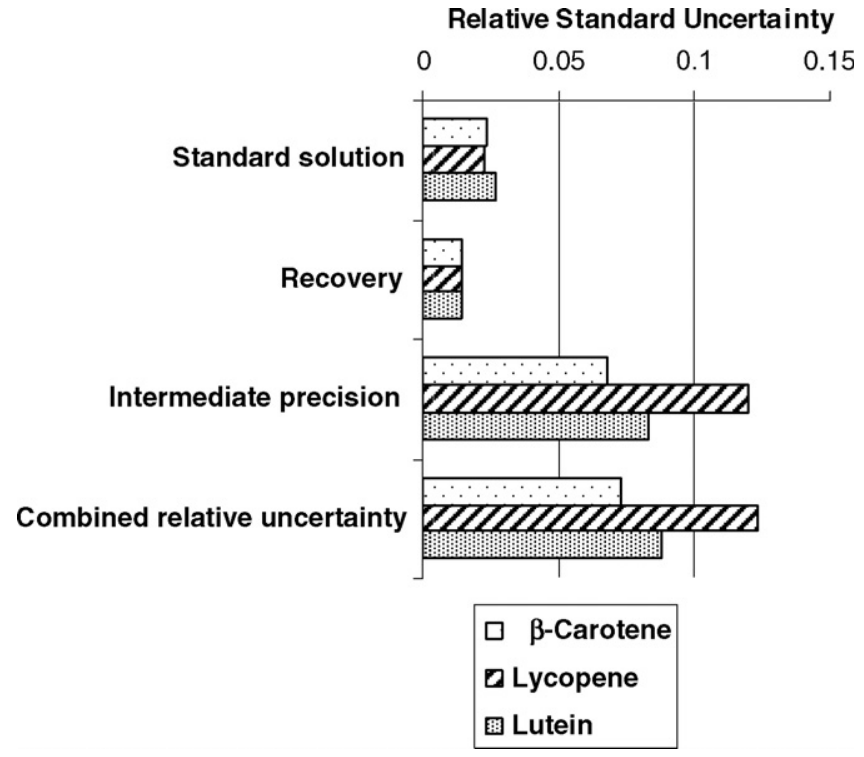

Fig. 2. Uncertainties histogram.

was intermediate precision as expected, because it includes random errors from many variables.

Expanded uncertainty was calculated for a level of confidence of approximately $95 \%$ considering a coverage factor of 2, because when assuming infinite degrees of freedom $t$-Student distribution tends to a normal distribution. Results are presented in Table 4.

Table 3

Small-scale within-region carotenoids variability

\begin{tabular}{|c|c|c|c|}
\hline & $\begin{array}{l}\text { Trans- } \beta \text {-Carotene } \\
(\mathrm{mg} / 100 \mathrm{~g})\end{array}$ & $\begin{array}{l}\text { All-lycopene } \\
(\mathrm{mg} / 100 \mathrm{~g})\end{array}$ & $\begin{array}{l}\text { Lutein } \\
(\mathrm{mg} / 100 \mathrm{~g})\end{array}$ \\
\hline \multicolumn{4}{|l|}{ Subfields } \\
\hline 1 & 1.0586 & 8.9323 & 0.1020 \\
\hline 2 & 1.0431 & 9.0746 & 0.0900 \\
\hline 3 & 1.0406 & 8.3067 & 0.1393 \\
\hline 4 & 0.9714 & 7.7473 & 0.0804 \\
\hline 5 & 0.9460 & 8.5847 & 0.0781 \\
\hline 6 & 0.8641 & 6.7744 & 0.0882 \\
\hline 7 & 0.8697 & 7.8093 & 0.1242 \\
\hline 8 & 0.9954 & 7.7335 & 0.0727 \\
\hline 9 & 0.9006 & 8.1262 & 0.0916 \\
\hline 10 & 0.8972 & 7.9303 & 0.0945 \\
\hline 11 & 0.8782 & 6.9859 & 0.1309 \\
\hline 12 & 1.1763 & 9.3306 & 0.0786 \\
\hline Mean & 0.97 & 8.1 & 0.10 \\
\hline $\begin{array}{l}\text { Standard } \\
\text { deviation (s) }\end{array}$ & 0.096 & 0.79 & 0.022 \\
\hline $\begin{array}{r}\text { Relative standard } \\
\text { deviation (rsd) }\end{array}$ & 9.9 & 9.7 & 23 \\
\hline $\begin{array}{l}\text { Analytical } \\
\text { measurement } \\
\text { uncertainty }(\mathrm{u})\end{array}$ & 0.070 & 1.0 & 0.0086 \\
\hline $\begin{array}{l}\text { Variability } \\
\text { significance } \\
\text { test }(F \text {-test })\end{array}$ & $\begin{array}{l}\text { Significant }^{*} \\
(F=1.97)^{* *}\end{array}$ & $\begin{array}{l}\text { Not significant } \\
(F=1.61)^{* * *}\end{array}$ & $\begin{array}{l}\text { Significant } \\
(F=6.64)^{* *}\end{array}$ \\
\hline
\end{tabular}


Table 4

Carotenoids content of two tomato varieties

\begin{tabular}{|c|c|c|c|c|c|c|}
\hline & $\begin{array}{l}\text { trans- } \alpha \text {-Carotene } \\
(\mathrm{mg} / 100 \mathrm{~g})\end{array}$ & $\begin{array}{l}\text { trans- } \beta \text {-Carotene } \\
(\mathrm{mg} / 100 \mathrm{~g})\end{array}$ & $\begin{array}{l}\beta \text {-Cryptoxanthin } \\
(\mathrm{mg} / 100 \mathrm{~g})\end{array}$ & $\begin{array}{l}\text { All-lycopene } \\
(\mathrm{mg} / 100 \mathrm{~g})\end{array}$ & $\begin{array}{l}\text { Lutein } \\
(\mathrm{mg} / 100 \mathrm{~g})\end{array}$ & $\begin{array}{l}\text { Zeaxanthin } \\
(\mathrm{mg} / 100 \mathrm{~g})\end{array}$ \\
\hline Tomato & & & & & & \\
\hline $\begin{array}{l}\text { Lycopersicon esculentum } \\
\text { M. var. Lido }\end{array}$ & $<0.008$ & $1.0 \pm 0.14(0.21)^{*}$ & $<0.006$ & $8 \pm 2.0(1.7)^{*}$ & $0.10 \pm 0.017(0.049)^{*}$ & $<0.008$ \\
\hline Tomato & & & & & & \\
\hline $\begin{array}{l}\text { Lycopersicon esculentum } \\
\text { M. var. "for salad" }\end{array}$ & $<0.008$ & $0.39 \pm 0.056$ & $<0.006$ & $2.3 \pm 0.57$ & $0.08 \pm 0.015$ & $<0.008$ \\
\hline
\end{tabular}

*Values between () include small-scale within-region variation.

\subsection{Small-scale within-region carotenoids variability}

The results from the 12 tomato samples harvested in the same region are shown in Table 3.

The comparison of $u_{\mathrm{c}}^{2}$ with $s^{2}$ through a $F$-test, allowed to conclude that, at a significance level of $5 \%$, they are significantly different for $\beta$-carotene and lutein and not significantly different for lycopene, suggesting that carotenoids ( $\beta$-carotene and lutein) content in tomato is affected by localization (factors such as luminosity, geochemical, etc.) even for a small-scale geographical variation. Localization natural variation from even a very small-scale plantation can be more relevant than uncertainty arriving from the analytical steps. The contribution of the analytical measurement result to the total variance (ratio of analytical measurement variance to total variance $\left.\left(u_{\mathrm{c}}^{2} / s^{2}\right)\right)$ is $15.1 \%$ for lutein and $54.2 \%$ for $\beta$-carotene. Lycopene is the most unstable of the studied carotenoids and the method is less sensitive for it, therefore, non-significant differences between partial and total variances can eventually be a consequence of such a high measurement uncertainty that can mask the variations deriving from luminosity/geochemical conditions.

\subsection{Tomato carotenoid content and uncertainty}

Carotenoid content of two different tomato varieties and associated uncertainties at a level of confidence approximately $95 \%$ are presented in Table 4 .

Trans- $\beta$-carotene content of analysed tomato samples $(0.39 \mathrm{mg} / 100 \mathrm{~g}$ and $1.0 \mathrm{mg} / 100 \mathrm{~g})$ agree with values observed by other authors for other tomato varieties, $0.349-1.702 \mathrm{mg} / 100 \mathrm{~g}$ in 11 varieties (Hart \& Scott, 1995) and $0.393-0.494 \mathrm{mg} / 100 \mathrm{~g}$ in 3 varieties (Granado, Olmedilla, Blanco, \& Rojas-Hidalgo, 1992). Lycopene seems to be prone to major variations with variety; analysed samples showed values of 2.3 and $8 \mathrm{mg} / 100 \mathrm{~g}$ while the above mentioned authors found, $1.582-5.653 \mathrm{mg} / 100 \mathrm{~g}$ and 1.604 $62.273 \mathrm{mg} / 100 \mathrm{~g}$, respectively.

The obtained results indicate that primary sampling seems to be the main source of uncertainty for tomato carotenoids content and dominates analytical sources such as analytical determination or sub-sampling of test materials within the laboratory. Recognizing sampling as the first step in the measurement process there is a need to include its contribution in the estimation of an overall uncertainty. Having in view the production of results to food composition table, this will give more realistic estimates of the uncertainty than consideration of the lab-based analytical procedures alone. Carotenoid values included in food composition tables are apparently very precise (expressed with many digits which may not be significant figures) however, when analytical uncertainty, variety, growth conditions, etc. are considered, such figures may be unrealistic, as demonstrated for tomato by estimating uncertainties.

Considering the sampling distribution of the mean for $\mathrm{n}$ samples as normal, $95 \%$ of the sample means lie in the interval $[\mu-1.96(\sigma / \sqrt{n}), \mu+1.96(\sigma / \sqrt{n})]$. With $n$ smaller than required by normal distribution, using $s$ to estimate $\sigma$ involves the substitution of 1.96 for $t$ at $n-1$ degrees of freedom. Rearranging the above expression and taking $\left(x_{\text {mean }}-\mu\right) / x_{\text {mean }}$ as a measure of the accuracy, the optimum sample size can be calculated as $n \geqslant\left(t_{\alpha, n-1}\right)^{2} \mathrm{~s}^{2} /$ (accuracy $\left.x_{\text {mean }}\right)^{2}$ (Greenfield \& Southgate, 2003). Based on these results, for an accuracy of $0.1, n$ will be 5 for the determination of $\beta$-carotene and lycopene and approximately 20 for lutein. Nevertheless, as tomato has a very low concentration of lutein and since there are other good sources of this carotenoid, it may be considered not to apply so many resources in its determination. For an accuracy of 0.05 , the number of samples would be 19 for $\beta$-carotene and lycopene.

\section{Conclusions}

HPLC has allowed good separation of all carotenoids intended to be analysed.

In this work repeatability limits, for the tomato matrix, were $0.043 \mathrm{mg} / 100 \mathrm{~g}$ for $\beta$-carotene (sample concentration $0.39 \mathrm{mg} / 100 \mathrm{~g}$ ), $0.38 \mathrm{mg} / 100 \mathrm{~g}$ for lycopene (sample concentration $2.3 \mathrm{mg} / 100 \mathrm{~g}$ ) and $0.0067 \mathrm{mg} / 100 \mathrm{~g}$ for lutein (sample concentration $0.076 \mathrm{mg} / 100 \mathrm{~g}$ ) and the relative standard deviations of the intermediate precision, were, for the same sample concentrations, $6.8 \%, 11.7 \%$ and $3.4 \%$, respectively.

Trueness studies showed good laboratory performance.

Tomato samples can be stored at least $24 \mathrm{~h}$ at $4{ }^{\circ} \mathrm{C}$ or $48 \mathrm{~h}$ at $-21^{\circ} \mathrm{C}$, before grinding. Standards and sample solutions can be stored at least $24 \mathrm{~h}$ at $4{ }^{\circ} \mathrm{C}$ and only up to $6 \mathrm{~h}$ at $36^{\circ} \mathrm{C}$. 
Carotenoid concentration varied largely with tomato variety (for the two different analysed varieties, lycopene variation coefficient was $113 \%$ ).

Variations on tomato carotenoid content introduced by small-scale differences on geographical factors, e.g. geochemical or luminosity, are very important and can easily overshadow contributions from the analytical process (sample homogenization, sample extraction, HPLC system measurement).

Improvement of the analytical method for lycopene, the most unstable of the studied carotenoids, is required in order to enable detection of possible location influence on lycopene content in tomato.

Based on this study, in order to determine carotenoids in tomato from the region under study 5 primary samples would be sufficient to estimate the population mean value with a level of confidence of $95 \%$ and $10 \%$ accuracy.

\section{Acknowledgments}

The authors thank Dr. Joaquim Castro Nogueira for supplying var. Lido tomato samples. M. Graça Dias is grateful to Instituto Nacional de Saúde Doutor Ricardo Jorge for providing the research fellowship BIC 01/2003-II.

\section{References}

Analytical Methods Committee. (1995). Uncertainty of measurement: implications of its use in analytical science. Analyst, 120, 2303-2308.

Barwick, V. J., \& Ellison, S. L. R. (1999). Measurement uncertainty: Approaches to the evaluation of uncertainties associated with recovery. Analyst, 124, 981-990.

Britton, G. (1995). Structure and properties of carotenoids in relation to function. FASEB Journal, 9, 1551-1558.

Cooper, D. A. (2004). Carotenoids in health and disease: Recent scientific evaluations, research recommendations and the consumer. Journal of Nutrition, 134(1), 221S-224S.

Di Mascio, P., Kaiser, S., \& Sies, H. (1989). Lycopene as the most efficient biological carotenoid singlet oxygen quencher. Archives of Biochemical and Biophysics, 274, 532-538.

EURACHEM/CITAC Guide CG4: Quantifying Uncertainty in Analytical Measurement (2000) (2nd ed.), www.eurachem.ul.pt.

Eurolab. (2002). Technical Report No. 1/2002. Measurement uncertainty in testing - a short introduction on how to characterise accuracy and reliability of results including a list of useful references. Eurolab Technical Secretariat; Berlin, Germany, 27 p.
Granado, F., Olmedilla, B., Blanco, I., \& Rojas-Hidalgo, E. (1992). Carotenoid composition in raw and cooked Spanish vegetables. Journal of Agriculture and Food Chemistry, 40, 2135-2140.

Granado, F., Olmedilla, B., Blanco, I., \& Rojas-Hidalgo, E. (1996). Major fruits and vegetables contributors to the main carotenoids in the Spanish diet. European Journal of Clinical Nutrition, 50, 246-250.

Greenfield, H., \& Southgate, D. A. T. (2003). Food composition data: Production, management and use (2nd ed.). Rome, Italy: FAO Publishing Management Service.

Hart, D. J., \& Scott, K. J. (1995). Development and evaluation of an HPLC method for the analysis of carotenoids in foods, and the measurement of the carotenoid content of vegetables and fruits. Food Chemistry, 54, 101-111.

ISO (1995). Guide to the expression of uncertainty in measurement (GUM). International Organization for Standardization, Geneva, Switzerland.

ISO $5725-1$ to 6 (1994(E)). Accuracy (trueness and precision) of measurement methods and results. International Organization for Standardization, Geneva, Switzerland.

ISO 8466-1 (1990(E)). Water quality - Calibration and evaluation of analytical methods and estimation of performance characteristics. International Organization for Standardization, Geneva, Switzerland.

IUPAC Commission on Nomenclature of Organic Chemistry and the IUPAC-IUB Commission on Biochemical Nomenclature (1974). Nomenclature of carotenoids. Retrieved on 2004-06-01: http:// www.chem.qmul.ac.uk/iupac.carot/.

Krinsky, N. I., \& Johnson, E. J. (2005). Carotenoid actions and their relation to health and disease. Molecular Aspects of Medicine, 26, $459-516$.

Miller, J. C., \& Miller, J. N. (1993). Statistics for analytical chemistry (3rd ed., 233 p.). West Sussex, Great Britain: Ellis Harwood Limited.

Olmedilla, B., Granado, F., Blanco, I., \& Rojas-Hidalgo, E. (1992). Determination of nine carotenoids, retinol, retinyl palmitate and $\alpha$ tocopherol in control human serum using two internal standards. Food Chemistry, 45(3), 205-213.

Riso, P., Visioli, F., Erba, D., Testolin, G., \& Porrini, M. (2004). Lycopene and vitamin $\mathrm{C}$ concentrations increase in plasma and lymphocytes after tomato intake. Effects on cellular antioxidant protection. European Journal of Clinical Nutrition, 58, 1350-1358.

Rodriguez-Amaya, D. B. (2000). Some considerations in generating carotenoid data for food composition tables. Journal of Food Composition and Analysis, 13, 641-647.

Scott, K. J., Finglas, P. M., Seale, R., Hart, D. J., \& Froidmont-Görtz, I. (1996). Interlaboratory studies of HPLC procedures for the analysis of carotenoids in foods. Food Chemistry, 57(1), 85-90.

Silva, R. J. N. B., Santos, J. R., \& Camões, M. F. G. F. C. (2006). A new terminology for the approaches to the quantification of the measurement uncertainty. Accreditation and Quality Assurance, 10(12), 664-671.

Weisburger, J. H. (2002). Lycopene and tomato products in health promotion. Experiments in Biology and Medicine, 227, 924-927. 